\title{
Modeling of membrane bioreactor treating hypersaline oily wastewater by artificial neural network
}

\begin{abstract}
A membrane sequencing batch reactor (MSBR) treating hypersaline oily wastewater was modeled by artificial neural network (ANN). The MSBR operated at different total dissolved solids (TDSs) $(35,000 ; 50,000 ; 100,000 ; 150,000 ; 200,000 ; 250,000 \mathrm{mg} / \mathrm{L})$, various organic loading rates (OLRs) $(0.281,0.563,1.124,2.248$, and $3.372 \mathrm{~kg} \mathrm{COD} /(\mathrm{m} 3 \mathrm{day}))$ and cyclic time $(12,24$, and $48 \mathrm{~h})$. A feed-forward neural network trained by batch back propagation algorithm was employed to model the MSBR. A set of 193 operational data from the wastewater treatment with the MSBR was used to train the network. The training, validating and testing procedures for the effluent COD, total organic carbon (TOC) and oil and grease $(\mathrm{O} \& \mathrm{G})$ concentrations were successful and a good correlation was observed between the measured and predicted values. The results showed that at OLR of $2.44 \mathrm{~kg} \mathrm{COD} /(\mathrm{m} 3$ day), TDS of 78,000 mg/L and reaction time (RT) of $40 \mathrm{~h}$, the average removal rate of COD was 98\%. In these conditions, the average effluent COD concentration was less than $100 \mathrm{mg} / \mathrm{L}$ and met the discharge limits.
\end{abstract}

Keyword: Membrane bioreactor; Artificial neural network; Hypersaline oily wastewater; Halophilic microorganisms; Modeling 